\title{
FLOUR AND BREAD
}

$\mathrm{T}$ HE 110th meeting of the Nutrition Society was held during July 5-6 in the Anatomy School, Cambridge. It took the form of a symposium on "Flour and Bread". In his introductory remarks the chairman, Sir Rudolph Peters, expressed the hope that the symposium would lead to a better appreciation of the essential facts on bread and flour and that discussion would be free from bias.

Dame Harriette Chick then summarized the fascinating history of wheat cultivation and breadmaking from antiquity onwards, emphasizing that until comparatively recent times white bread was generally desired, being a sign of wealth and refinement. The unconventional, however, have always attributed health-giving virtues to the darker bread of the country follk, though there could formerly have been no informed arguments in support of this opinion, and the darkness of the country bread was due no less to inclusion of rye, barley, or even legumes, than to the use of meal of higher extraction. Furthermore, the refined flours from stone-milling must have contained more germ and aleurone layer than modern roller-milled white flour; the latter by the end of the nineteenth century was the common food of the British people.

Earlier scientific work on flour dealt with chemical and physical properties of its proteins-particularly of the gluten because of its importance in baking technology. From the middle of the past century, however, the nutritive value of the different parts of the grain has been studied. Dame Harriette emphasized the merits of the work during 1883-84 of Rubner and of Girard, particularly in showing the high protein content of the aleurone layer which in milling is separated with the bran. Later workers have shown that $80-90$ per cent of this protein is available to human subjects. The proteins in wheat bran are richer than those of white flour in two of the essential amino-acids, namely, lysine and tryptophan, which is why animal-feeding experiments have shown that the value of white-flour protein is increased by the presence of a little bran.

The uneven distribution, in the grain, of essential nutrients other than protein was discovered about the period of the First World War. After recalling the pioneer researches on the cause of beriberi among rice-eaters, Dame Harriette mentioned that this disease, which at the time was puzzling the authorities, was diagnosed among Commonwealth troops on Lemnos by Col. C. J. Martin, at that time director of the Lister Institute ; their diet had mainly been white bread and tinned meat. This led to the finding that the anti-beriberi factor was concentrated in the germ of both wheat and rice. The specification for 85 per cent National flour, recommended by the Accessory Food Factors Committee of the Lister Institute and the Medical Research Council, was a satisfactory compromise in that, while the nutritive value of the flour approached that of a 100 per cent meal, its fibre content was nearer to that of white flour. Research at the Research Association of British Flour-Millers had shown that the detail of this recommendation could be achieved in practice.

Dr. C. R. Jones used a simplified flow-sheet to explain the essentials of the flour-milling process and discussed the differences in nutrient content between the various flour streams that together form the straight-run flour. The compositions of these streams at different extraction-rates were shown. Vitamin $\mathbf{B}_{1}$, in particular, is largely contained in a small proportion of the total flour from the end of the milling system, which incidentally is of poor bread-making quality. Data were given in illustration of the point that, even at a given extraction-rate, the 'natural' contents of nutrients in straight-run flour may vary considerably.

In a discussion that clearly greatly entertained her audience, Miss E. M. Widdowson considered some of the factors affecting the planning of human nutritional experiments and the difficulties encountered. She stressed that, in the first instance, it is well worth while to plan the perfect experiment, and then see how nearly the design can be put into practice. While avowing that the investigator should include himself among the experimental subjects, Dr. Widdowson remarked that any sort of nutritional experiment is bound to curtail one's social activities. Thus, the balance experiments in connexion with the effects of phytic acid in brown flour on calcium absorption lasted for nearly a year, with only one week-end free every four weeks. Particular difficulties encountered in the celebrated German experiments included the overcoming of a belief by those in charge of one home that it was morally wrong to allow children to eat ad lib. In one orphanage, where bread was given in addition to the inadequate German rations, the children grew less well than a similar group in another orphanage where no extra food was given. The reason was ascribed to the unsympathetic personality of the woman in charge of the first group; the children actually ate the extra food but failed to benefit from it.

Subsequent discussion showed that this last observation had created much interest. Mr. A. L. Bacharach inquired whether any data showing the effects of emotional disturbance had been obtained from animal feeding trials. Prof. R. A. MeCance reminded the meeting that the secretions of the thyroid and pituitary glands may be affected by 'nerves'. Points made by other speakers were that a negative nitrogen balance is associated with emotional disturbance and that hospital experience shows that anxiety causes increased excretion of fat. Both the chairman and Dame Harriette refuted any suggestion that animal experiments are without sig. nificance in human nutrition by recalling signal discoveries made originally by means of experiments on animals.

Dr. Neil Jenkins, referring to the absence of evidence in support of the belief that high carbohydrate consumption promotes dental decay, and that brown bread is better than white in this respect, offered the following two suggestions. Flour, or bread, texture may be important; the extent to which food debris adheres to teeth is less after eating brown than after eating white bread. He also recalled T. B. Osborne's postulate that bran contains a factor that hinders attack on teeth by acids. Jenkins suggested this may be a phytate, since he has found that phytates reduce the rate at which 
calcium in extracted teeth will dissolve in acid media.

Prof. R. A. Morton recalled the formation of the Panel on Composition and Nutritive Value of Flour under the chairmanship of Sir Henry Cohen (now Lord Cohen of Birkenhead), of which he was a mem. ber, and gave a most interesting account of its considerations and conclusions. $\mathrm{He}_{\theta}$ stressed the consideration that while the adoption of an 80 per cent flour might conceivably ensure against possible but as yet unknown shortages in the diet, the enrichment of white flour would give more positive protection against clearly defined deficiency states. $\mathrm{H}_{\Theta}$ personally was impressed by the hazy nature of the current assessment of requirements of several nutrients, especially in view of the possible occurrence of side-reactions.

Dr. H. M. Sinclair pointed out that flour, or bread, is the most important single item of diet in Britain. In 1947,85 per cent extraction flour provided 27 per cent of calories consumed, 37 per cent of protein and about the same proportion of requirements of $B_{1}$, iron, phosphorus and nicotinic acid. Of the nutrients excluded from the present enrichment scheme, he considered that riboflavin was more important than was recognized by the Post-War Loaf Conference. As a single source of supply of riboflavin, bread is more important even than milk. He suggested that, if we must have white flour, riboflavin should be included in the enrichment policy, as in the United States and Canada.

As to whether, in other respects, enriched 70 per cent is equivalent to high-extraction flour, a table was presented showing that the contents of pyridoxin, biotin, folic acid, linoleic acid and vitamin $\mathrm{E}$ ( $\alpha$-tocopherol) were all materially lower in the white flour; only in the case of pantothenic acid was there no appreciable difference. In Dr. Sinclair's opinion, pyridoxin, linoleic acid and vitamin $\mathrm{E}$ have been grossly neglected and are very important in human nutrition. High-extraction flour is the most important single source of pyridoxin; but a decreased extraction-rate causes a serious reduction in our intake. On the other hand, judging from recently reported work with monkeys, human requirements may be met only to the extent of about one-third, even with 80 per cent extraction flour.

Dr. Sinclair tentatively estimates the contents of linoleic acid in 80 per cent and in 72 per cent flour as 0.8 and 0.5 per cent, respectively. Normally it is protected, both from atmospheric oxidation, and during body metabolism, by its accompanying vitamin $\mathbf{E}$. The consideration may therefore be important that not only is vitamin $\mathbf{E}$ present initially to a smaller extent in white flour but also it is in any event destroyed by bleaching. Moreover, bleaching may not only destroy the essential-fatty-acid activity of the linoleic acid in flour but also may convert this substance into an antagonist that might increase the essential-fatty-acid requirement. Essential-fatty-acid deficiency might arise from dietary deficiencies in respect of linoleic acid, or of pyridoxin, or of vitamin $\mathrm{E}$, since these are functionally interrelated, and in Dr. Sinclair's view it may be relevant to a variety of diseases of civilization, including coronary thrombosis and dental caries.

Dr. D. W. Kent-Jones, in presenting "The Case for Fortified White Flour", stressed the importance of the preference of the British public for white bread as against even the slightly darker 80 per cent extraction flour. It must also be remembered that destruction of certain nutrients occurs in cooking and baking, and only 65 per cent of all flour milled is made into bread; the rest is used for cakes, biscuits, home cooking, etc. The respective merits of breads made from long extraction and from enriched white flours had been comprehensively considered by the Cohen Committee, which took into account the Wid. dowson-McCance Report on the German experiments that may well be regarded as decisive. Nevertheless, the levels of fortification originally suggested by the Post-War Loaf Conference are now under reexamination by the Food Standards Committee, which is also considering whether fortification with riboflavin should be carried out. In presenting revised values for the contents of various $B$ vitamins in flours of different extractions, Dr. Kent-Jones pointed out that lower-extraction flours are by no means devoid of the rarer components of the $\mathrm{B}$ complex; he also stressed that we know little of the actual daily requirements of most of them. He emphasized the importance of the Newfoundland experiment on the effects of white flour, enriched on the American scale, and of enriched margarine. This lasted more than four years, three hundred subjects being carefully examined before and after the experiment, during which visible signs of malnutrition, and also various mortality-rates, decreased. Moreover, quoting Wilder, "the quality of life had improved in Newfoundland". Dr. Kent-Jones also stressed that, in baking, half the vitamin $E$ is destroyed, and in any event, cereals do not contribute much vitamin $\mathrm{E}$ to the diet.

A paper by J. R. Nicholls and J. R. Frazer, which was read by Dr. Nicholls, discussed analytical problems in the determination and control of extractionrates of flour. Although extraction-rate is not an absolute yardstick for defining the grade of a flour, the term is widely used in industry and generally understood. The basic difficulty in its determination, by analysis of a sample, is that although 100 per cent extraction flour contains the whole of the bran, flours of lower extraction contain only selected fractions of the bran layers, which may differ in chemical composition from whole bran.

The authors reviewed various chemical constituents of flour and wheat and showed that none is strictly applicable to the determination of extractionrate. The only practical course is to judge analytical values obtained on a given sample against corresponding data accumulated from an extensive survey of samples, having regard to the coefficient of variation found for each value. There is, however, a particular interest attached to the determination of starch, since this is provided practically entirely by the endosperm, while other carbohydrates are distributed to varying extents throughout the grain. The starch content of the endosperm is affected by the protein content, which varies considerably between wheats, but the ratio of non-starch carbohydrate to the sum of starch plus protein was offered as an approximate index of flour grade. Values for this index appeared characteristically dependent on extraction-rate and fairly independent of type of grist.

In opening the final discussion, the chairman acknowledged the differences in points of view and even in basic data offered by the several contributors, but hoped that these would be subjected to further scientific examination. Regarding the German 
experiment by Widdowson and McCance, he emphasized the possible significance of the soup supplied to the children as a source of important nutrients.

Dr. B. S. Platt challenged Dr. Kent-Jones's con. clusion from the Newfoundland experiment that, in view of the health improvement found, highextraction flour could have contributed no more than the enriched white flour actually used. The Wilder report had stated "not all the outward signs of malnutrition had decreased in prevalence. Only those had lessened which could have been affected by addition of vitamin $A$ to margarine and of riboflavin, niacin and thiamine $\left(B_{1}\right)$ to the flour'. In replying, Dr. Kent-Jones interpreted Wilder as attributing the persistent signs to vitamin $\mathrm{C}$ deficiency, not to deficiencies for which the flour could have been held responsible.

Dr. E. Kodicek emphasized that a proportion of nicotinic acid in cereals is in the bound form and unavailable to a number of animals. On the other hand, nicotinic acid added by way of enrichment is wholly available.

Several contributors queried the claim that the public strongly preferred bread made from white flour to that from higher-extraction flour. In this connexion, Dr. J. B. M. Coppock referred to published evidence in support of the claim which had been obtained in a comprehensive survey on consumer preference recently carried out in Glasgow.

The relevance or otherwise of mortality statistics in relation to modern food habits and processing techniques was discussed both by Prof. J. J. Yudkin and Dr. Sinclair. The meeting ended appropriately with a plea by Mr. Bacharach for liberty of choice : members, he said, are free to express views but should not seek to force their adoption.

C. R. JONES

\section{INSTITUTE OF BIOLOGY CONVERSAZIONE}

T

HE annual conversazione of the Institute of Biology, London Branch, was held at the Imperial College of Science and Technology on the evening of June 25. Members and their guests were received in the Students' Union by Prof. P. H. Gregory (head of the Botany Department), F. Howarth (assistant director of the Botanical Laboratories) and Dr. H. O. J. Collier (chairman of the London Branch). A diversity of exhibits was displayed in the Botany Department, by courtesy of Prof. Gregory.

The word 'conversazione' has an Italian derivation and can be defined as a meeting of people for conversation and discussion, particularly on literary, scientific, antiquarian or artistic subjects. The emphasis is, therefore, on the facilities for social intercourse: these were admirably provided in the newly built Students' Union. To say that exhibits take second place to discussion at such a function is not to detract from their importance, for they them. selves are the chief topies of conversation.

The Linnean Society of London, this year's guest society, provided an exhibit illustrating the evolution of the "Species Plantarum" by means of books and manuscripts, as well as items from Linnaeus's natural history collection, including insects, shells and plants. In addition, some of his own annotated works were exhibited and a map of the world showing journeys undertaken by his students to make collections. This was appropriate in the year of the 250th anniversary of the birth of Carl Linné, and provided an interesting comparison with 'Huxleyana', an exhibit showing some of the work of T. H. Huxley and presented by the Zoology Department of the Imperial College.

Each year the London Branch invites one firm of biological suppliers to provide a trade-stand, which, this year, was devoted to stains and reagents for microscopy, modern mounting media, water analysis tablets for field ecology and so on, presented by Edward Gurr, Ltd. Specimen publications were displayed by the Universities Federation for Animal Welfare, the quarterly journal Medical and Biological Illustration and the Institute of Biology. The London Branch's own exhibits included photographs taken during a week-end excursion to the Severn Wildfowl Trust and new trends in biological education.

It is not easy to decide which of the forty or more members' and guests' exhibits most deserve mention. Certainly one of the most original was a 'self-reproducing analogue' (Prof. L. S. Penrose and R. Penrose) recently described in Nature $(179,1183 ; 1957)$. Various suitably shaped wooden or plastic objects, when shaken in a trough, generate precise copies of themselves. The process has been termed pseudobiosynthetics.

Living animals always attract interest and were a feature of several exhibits. In one (P. Hunter-Jones) normal hoppers and adults of the desert locust (Schistocerca gregaria), reared either in crowded conditions or in isolation-phases gregaria or solitariawere compared with albino strains raised under similar conditions. In another (A. T. Thompson) could be seen representatives of some of the exotic grasshoppers kept at the Anti-Locust Research Centre. Cultures were shown of Pharaoh's ant (Monomorium pharaonis) (A. A. Green) and of the American dampwood termite Zootermopsis angusticollis (W. V. Harris and R. M. C. Williams). This insect provides a useful laboratory source of large protozoa, especially species of the genus Trichonympha.

Insects also appeared in exhibits of important species of tsetse fly with distribution maps and colour transparencies of their breeding habitats (Dr. J. R. Busvine), the biology of a British 'ambrosia beetle' (J. M. Baker), the use of 'Terylene' netting for studying the pattern of emergence and decay in a wheat bulb-fly population (J. W. Stephenson and R. W. Dobson) and in preparations of the genitalia of certain beetles (L. P. Lefkovitch). The effect of gamma-rays on ovarian development in the tsetse fly, Glossina morsitans, was illustrated by slides showing the ovaries of a 33-day-old female from an irradiated pupa, which were less developed than those of a 3-day-old female from a normal pupa (W. H. Potts).

In the fields of microbiology were exhibits of membrane filter techniques for concentrating and counting micro-organisms and new selective culture media (W. H. Pierce), some superb photographs of mammalian gametes (Dr. M. W. H. Bishop and Dr. C. R. Austin), preparations showing the cell structure of Cyanophyceae (Dr. J. K. Spearing), an antibody to Trypanosoma vivax present in normal cotton rat serum (Dr. R. J. Terry and Miss V. M. Smith), and tests for the antibiotic sensitivity of bacteria (W. A. Freeman). 